\title{
ALONGAMENTO DE PLANTAS DE Dendrobium nobile Lindl. COM PULVERIZAÇÃO DE ÁCIDO GIBERÉLICO ${ }^{1}$
}

\author{
Elongation of Dendrobium nobile Lindl. plants by gibberellic acid pulverization
}

\begin{abstract}
Mívia Rosa de Medeiros Vichiato ${ }^{2}$, Marcelo Vichiato ${ }^{3}$, Daniel Melo de Castro ${ }^{4}$, Leonardo Ferreira Dutra ${ }^{5}$, Moacir Pasqual ${ }^{6}$

\section{RESUMO}

Dendrobium nobile Lindl. (olho-de-boneca) é uma das orquídeas mais populares do Brasil, ocupando posição de destaque no mercado de plantas de corte e de vaso. Entretanto, o desenvolvimento muito lento da família Orchidaceae tem contribuído para o elevado valor unitário de suas plantas, sendo necessárias técnicas que promovam a obtenção mais rápida de plantas comercializáveis. Objetivando avaliar o efeito do ácido giberélico no alongamento de plantas de $D$. nobile, foi realizado experimento em delineamento inteiramente casualizado com cinco concentrações de $\mathrm{GA}_{3}\left(0,50,100,200\right.$ e $\left.400 \mathrm{mg} . \mathrm{L}^{-1}\right)$ e treze repetições. Efetuaram-se quatro pulverizações com soluções de ácido giberélico a intervalos quinzenais e noventa dias após início dos tratamentos, avaliaram-se as seguintes características: altura e diâmetro do pseudobulbo, número de folhas, largura e comprimento das folhas. A aplicação do GA promoveu, em comparação às plantas testemunhas, incrementos de 64,08\% em altura e 44,27\% no comprimento das folhas e decréscimos de 50\% no diâmetro do pseudobulbo e 56,09\% na largura das folhas. Não houve diferença entre as concentrações de GA testadas. Portanto, o ácido giberélico nas concentrações de 50 a $400 \mathrm{mg} . \mathrm{L}^{-1}$ é igualmente eficiente no alongamento de plantas $D$. nobile.
\end{abstract}

Termos para indexação: Orchidaceae, $\mathrm{GA}_{3}$, regulador de crescimento, Dendrobium nobile.

\begin{abstract}
The Dendrobium nobile Lindl. (olho-de-boneca) is one of the most popular orchids of Brazil, occupying prominence position in the market of cut plants and pot. However, the very slow development of the family Orchidaceae has been contributing to the high unitary value of the plants, being necessary techniques that promote the fastest way of obtaining plants in the marketed. With the objective of evaluating the effect of the gibberellic acid in the elongation of plants of $D$. nobile spread by cutting, an entirely randomized experimental design was carried out with five concentrations of $\mathrm{GA}_{3}\left(0,50,100,200\right.$ and $\left.400 \mathrm{mg} \cdot \mathrm{L}^{-1}\right)$ and thirteen replications. They were made four sprays with $\mathrm{GA}_{3}$ solutions to biweekly intervals and ninety days after beginning of the treatments, the following characteristics were evaluated: height and diameter of the pseudobulbs, number of leaves, width and length of the leaves. The GA application promoted, in comparison with the control, increasings of $64,08 \%$ in height and $44,27 \%$ in the length of the leaves and decreasing of 50\% in the diameter of the pseudobulbs and $56,09 \%$ in the width of the leaves. There was no difference among the $\mathrm{GA}_{3}$ concentrations tested. Therefore, the giberelic acid in the concentrations from 50 to $400 \mathrm{mg}$. $\mathrm{L}^{-1}$ is efficient in the elongation of D. nobile plants.
\end{abstract}

Index terms: Orchidaceae, $\mathrm{GA}_{3}$, growth regulator, Dendrobium nobile.

(Recebido para publicação em 15 de julho de 2005 e aprovado em 24 de novembro de 2005)

\section{INTRODUÇÃO}

As orquidáceas são consideradas as mais antigas espécies ornamentais, sendo cultivadas tanto para produção de plantas de corte como de vaso (FARIA \& ILLG, 1998; FRÁGUAS et al., 2003; SHEEHAN, 1983). No entanto, as plantas dessa família apresentam desenvolvimento muito lento, requerendo maior período de cultivo antes de serem comercializadas. Isso tem contribuído para o elevado valor unitário de suas plantas no mercado. Assim sendo, existe grande interesse na diminuição do tempo de formação da muda de orquídea, principalmente, para a diminuição dos custos de produção.
O gênero Dendrobium apresenta mais de 1000 espécies, sendo considerado um dos maiores da família Orchidaceae. $\mathrm{O}$ interesse por esse gênero é devido à sua larga distribuição geográfica, crescimento em diferentes habitats e, principalmente, ao grande valor florístico de seus híbridos (JONES et al., 1998).

A giberelina $\left(\mathrm{GA}_{3}\right)$ ou ácido giberélico é um hormônio que atua nas plantas como estimulante de crescimento, originando plantas de maior tamanho em conseqüência da sua ação na divisão e expansão celulares. Em muitas espécies, a dominância apical das plantas acentua-se após as aplicações com o ácido giberélico (CORDEIRO, 1979; ROSSELL, 1971; TAIZ \& ZEIGER, 1998).

\footnotetext{
Parte da tese de doutorado da primeira autora, Universidade Federal de Lavras/UFLA - Cx. P. 3037 - 37.200-000 - Lavras, MG

${ }^{2}$ Bióloga, Doutoranda em Agronomia/Fitotecnia na Universidade Federal de Lavras/UFLA - Cx. P. 3037 - 37.200-000 - Lavras, MG - mivia@ig.com.br ${ }^{3}$ Engenheiro Agrônomo, Dr. em Agronomia/Fitotecnia na Universidade Federal de Lavras/UFLA - Cx. P. 3037 - $37.200-000$ - Lavras, MG vichiato@hotmail.com

${ }^{4}$ Professor Dr. do Departamento de Biologia da Universidade Federal de Lavras/UFLA - Cx. P. 3037 - 37.200-000 - Lavras, MG danielmec@hotmail.com

${ }^{5}$ Pesquisador Dr. da Embrapa CNPF - leodutra@cnpf.embrapa.br

${ }^{6}$ Professor Dr. do Departamento de Agricultura da Universidade Federal de Lavras/UFLA - Cx. P. 3037 - 37.200-000 - Lavras, MG - mpasqual@ufla.br
} 
O ácido giberélico é pouco solúvel em água e éter sulfúrico, e apresenta boa solubilidade em soluções de bicarbonato e acetato de sódio (APPLICATION..., 1996; ROSSELL, 1971). Não pode ser dissolvido em águas alcalinas, nem misturado com outros produtos fitofarmacêuticos, uma vez que as soluções de ácido giberélico são pouco estáveis. Além disso, a aplicação dessa solução é inviável quando existe previsão de chuva nas seis horas após a aplicação e/ou com temperaturas iguais ou superiores a $32^{\circ} \mathrm{C}$. A pulverização com ácido giberélico somente é aconselhável em culturas com bom estado de desenvolvimento vegetativo e, por causa do maior desenvolvimento das plantas, há necessidade de adubação suplementar (APPLICATION..., 1996; ROSSELL, 1971).

Em orquídeas, a giberelina é comumente utilizada no meio de cultura visando estimular o desenvolvimento do embrião, e também na indução do florescimento, mediante pulverização (CHEN et al., 1994). Em plantas intactas de Catasetum fimbriatum Lindl. \& Paxt. (Orchidaceae) cultivadas in vitro, sob 16 horas de luz, o GA 3 não promoveu aumento dos pseudobulbos (SUZUKI et al., 2004). No entanto, a pulverização com giberelina ainda não foi utilizada para o alongamento das plantas intactas.Com este trabalho, objetivou-se avaliar os efeitos da pulverização de $\mathrm{GA}_{3}$ nas concentrações de 0, 50, 100, 200 e 400 mg. $\mathrm{L}^{-1}$ no alongamento de plantas de Dendrobium nobile Lindl.

\section{MATERIAL E MÉTODOS}

O experimento foi conduzido em casa-de-vegetação do Departamento de Agricultura da Universidade Federal de Lavras-MG, no período de novembro de 2004 a fevereiro de 2005.

Foram utilizadas plantas de $D$. nobile com quatro meses de idade, cultivadas em vasos de polietileno de 500 $\mathrm{cm}^{3}$, contendo como substrato fibra de coco. As plantas apresentavam, em média, três folhas, $4,74 \mathrm{~cm}$ de altura, peso de 2,85 g, um broto com $6,07 \mathrm{~cm}$ de altura e foram mantidas em casa-de-vegetação, sobre bancada metálica. A irrigação foi feita de acordo com as condições de umidade do substrato sendo, em média, quatro vezes por semana, durante todo o experimento.

Efetuaram-se quatro pulverizações, realizadas pela manhã a intervalos quinzenais (COELHO et al., 1983), com 50, 100, 200 e $400 \mathrm{mg} . \mathrm{L}^{-1}$ de GA . A solução utilizada para a testemunhafoi água e Tween-80 a 0,01\%. As plantas foram intensamente molhadas com o tratamento, até ser atingido o ponto de escorrimento, conforme sugerido por Coelho et al. (1983), Leonel \& Rodrigues (1996) e Sidahmed (1978). Para aumentar a eficiência do ácido giberélico, foi adicionado Tween- 80 a $0,01 \%$ em todas as pulverizações (MENEGUCCI et al., 2001).

Utilizou-se delineamento inteiramente casualizado com cinco tratamentos e 13 repetições com uma planta por parcela, perfazendo um total de 65 parcelas.

Quatro dias após a primeira pulverização com ácido giberélico, foi realizada a primeira adubação. As adubações foram aplicadas semanalmente, via foliar, durante todo o experimento, utilizando o fertilizante comercial Biofert ${ }^{\circledR}$, na concentração de 5,0 mL.L $\mathrm{L}^{-1}$, aplicando-se 2,0 mL da solução por planta (ARAÚJO, 2004).

Noventa dias após a primeira pulverização, avaliaram-se as seguintes características dos brotos: altura do pseudobulbo (medida com régua graduada em milímetros e expressa em $\mathrm{cm}$ ), diâmetro do pseudobulbo (medido com paquímetro digital e expresso em $\mathrm{mm}$ ), número de folhas (obtido pela contagem de todas as folhas do broto), largura e comprimento das folhas (medido com paquímetro digital e expresso em $\mathrm{cm}$ ).

Os resultados obtidos nessas avaliações foram submetidos à análise de variância e as médias foram comparadas pelo teste de Scott Knott a 5\% de probabilidade, utilizando-se o programa Sisvar (FERREIRA, 2000).

\section{RESULTADOS E DISCUSSÃO}

Para todas as características avaliadas nas plantas de D. nobile tratadas com o fitorregulador, não houve diferença entre as concentrações de $\mathrm{GA}_{3}$ (Tabela 1 e Figura 1). Entre as plantas testemunhas e as tratadas com $\mathrm{GA}_{3}$, houve diferenças significativas $(\mathrm{P}<0,01)$ na altura e diâmetro dos pseudobulbos e no comprimento e largura das folhas de D. nobile (Tabela 1 e Figura 1).

O ácido giberélico promoveu crescimento do pseudobulbo de D. nobile (Tabela 1 e Figura 1). As plantas tratadas com o fitorregulador eram $64,08 \%$ mais altas $(13,75$ $\mathrm{cm})$ quando comparadas com as plantas testemunhas, com altura média de $8,38 \mathrm{~cm}$ (Tabela 1). Esses resultados estão de acordo com os trabalhos de Casper \& Taylor (1989), Coelho et al. (1983) e Leonel \& Rodrigues (1996).

A promoção de crescimento do pseudobulbo de $D$. nobile por $\mathrm{GA}_{3}$ deveu-se à sua ação no alongamento celular que, conseqüentemente, afetou o tamanho das plantas, concordando com Almeida \& Pereira (1996). Sachs et al. (1960) relataram que a aplicação de giberelina em caules produz aumento na divisão celular do meristema apical, promovendo a formação de grande número de células e o alongamento individual de cada célula. A aplicação de $\mathrm{GA}_{3}$ em caules também estimula o crescimento de tecidos jovens dos entrenós (CORDEIRO, 1979). 
TABELA 1 - Altura (AP), diâmetro, (DP), número de folhas (NF) e número de entrenós do pseudobulbo (NE) e comprimento $(\mathrm{CF})$ e largura da folha $(\mathrm{LF})$ de plantas de Dendrobium nobile tratadas com ácido giberélico. UFLA, Lavras-MG, 2005.

\begin{tabular}{|c|c|c|c|c|c|c|}
\hline $\begin{array}{c}\mathbf{G A}_{3} \\
\left(\mathbf{m g} \cdot \mathbf{L}^{-\mathbf{1}}\right)\end{array}$ & $\begin{array}{c}\text { Altura } \\
\text { (cm) }\end{array}$ & $\begin{array}{c}\text { Diâmetro } \\
\text { (mm) }\end{array}$ & $\begin{array}{l}\text { Número de } \\
\text { folhas }\end{array}$ & $\begin{array}{c}\text { Número de } \\
\text { entrenós }\end{array}$ & $\begin{array}{l}\text { Comprimento da } \\
\text { folha }(\mathrm{cm})\end{array}$ & $\begin{array}{l}\text { Largura da folha } \\
\qquad(\mathrm{cm})\end{array}$ \\
\hline 0 & $8,38 \mathrm{~b}$ & $7,00 \mathrm{a}$ & $4,07 \mathrm{a}$ & $6,15 \mathrm{a}$ & $5,33 \mathrm{~b}$ & $1,92 \mathrm{a}$ \\
\hline 50 & $13,69 \mathrm{a}$ & $4,15 \mathrm{~b}$ & $4,46 \mathrm{a}$ & $6,46 \mathrm{a}$ & $7,38 \mathrm{a}$ & $1,53 \mathrm{~b}$ \\
\hline 100 & $13,75 \mathrm{a}$ & $3,91 \mathrm{~b}$ & $4,83 \mathrm{a}$ & $6,75 \mathrm{a}$ & 7,07 a & $1,38 \mathrm{~b}$ \\
\hline 200 & $12,17 \mathrm{a}$ & $3,50 \mathrm{~b}$ & $3,83 \mathrm{a}$ & $6,08 \mathrm{a}$ & $7,23 \mathrm{a}$ & $1,23 \mathrm{~b}$ \\
\hline 400 & $13,53 \mathrm{a}$ & $3,92 \mathrm{~b}$ & $4,00 \mathrm{a}$ & $6,69 \mathrm{a}$ & $7,69 \mathrm{a}$ & $1,23 \mathrm{~b}$ \\
\hline C.V. (\%) & 16,80 & 27,31 & 22,66 & 13,37 & 12,36 & 30,83 \\
\hline
\end{tabular}

* Médias seguidas de letras distintas nas colunas, diferem entre si pelo Teste de Skott Knott a 5\% de probabilidade.

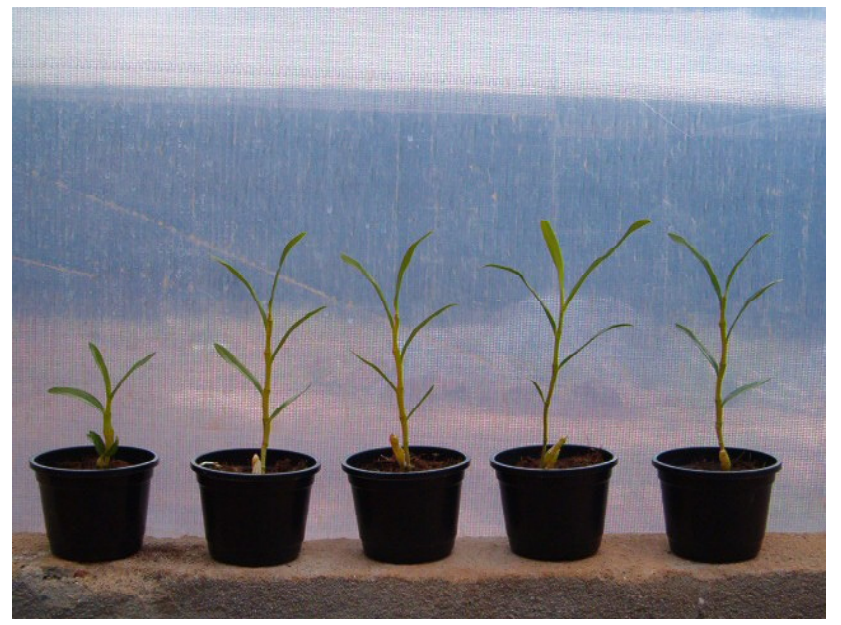

FIGURA 1 - Desenvolvimento de plantas de Dendrobium nobile tratadas com ácido giberélico nas concentrações 0 (A), 50 mg.L - $^{-1}$ (B), 100 mg.L-1 (C), 200 mg.L.-1 (D) e 400 mg.L-1 (E). UFLA, Lavras-MG, 2005. Barra = $10 \mathrm{~cm}$.

As plantas de D. nobile apresentavam, antes do tratamento, altura média de $6,07 \mathrm{~cm}$. Noventa dias após o início dos tratamentos, houve incremento de $2,31 \mathrm{~cm}$ $(38,05 \%)$ na altura das plantas testemunhas e de $7,68 \mathrm{~cm}$ $(126,52 \%)$ nas plantas tratadas com ácido giberélico (Tabela 1). Por esses resultados, constatou-se que plantas de $D$. nobile respondem favoravelmente ao tratamento com ácido giberélico. Um outro importante fator que pode ter contribuído para os efeitos positivos das giberelinas observados neste trabalho, é a época em que o experimento foi instalado (novembro / 2004). Para Meltivier (1986), o meio ambiente parece exercer efeito sobre a concentração de giberelinas. Segundo o autor, em condições de dias longos as plantas tendem a produzir mais giberelinas que em condições de dias curtos. Leonel \& Rodrigues (1996), que iniciaram seus experimentos no outono, que apresenta dias curtos, não observaram efeitos positivos das giberelinas no aumento em altura do caule das plantas intactas de Citrus limonia Osbeck.

Além da promoção de crescimento do pseudobulbo, as plantas de $D$. nobile tratadas com $\mathrm{GA}_{3}$ apresentaram coloração verde-clara, com folhas estreitas e pseudobulbo 
com diâmetro menor que o controle (Tabela 1), características também observadas por Almeida \& Pereira (1996).

O diâmetro dos pseudobulbos das plantas testemunhas foi $50 \%$ maior quando comparadas com as plantas tratadas (Tabela 1). A pulverização com GA diminuiu o diâmetro dos pseudobulbos de $D$. nobile provavelmente porque este é o principal órgão armazenador de água, carboidratos e nutrientes minerais das orquídeas epífitas (ZIMMERMAN, 1990). Como as giberelinas agem sobre o metabolismo dos carboidratos, estocados principalmente no pseudobulbo, o diâmetro do pseudobulbo diminuiu por causa da hidrólise de suas substâncias de reserva. Além disso, o acúmulo de carboidratos no tecido eleva a pressão osmótica, fazendo com que o fluxo de água, estocada principalmente no pseudobulbo, ocorra mais rapidamente para o interior da célula, favorecendo a sua expansão (CORDEIRO, 1979; DAYKIN et al., 1997; PIRES, 1998).

O número de entrenós dos pseudobulbos não foi influenciado pela pulverização com $\mathrm{GA}_{3}$ (Tabela 1). Esse resultado está de acordo com a literatura, em que um dos efeitos mais notáveis da giberelina é a promoção do alongamento do caule de plantas intactas, sem que haja aumento do número de entrenós (ALMEIDA \& PEREIRA, 1996; AURAS, 1997; SPONSEL, 1985).

Apesar do número de folhas não ter sido influenciado pela pulverização com $\mathrm{GA}_{3}$ (Tabela 1), enfatizase que após a segunda pulverização com o fitorregulador, sete dias após a primeira aplicação (inicialmente, planejavase a pulverização semanal), as plantas tratadas apresentaram folhas com coloração amarela, indicando efeitos de toxidez, perdendo algumas folhas. As pulverizações foram, por isso, realizadas quinzenalmente e as plantas não mais apresentaram esses sintomas. Portanto, era esperado que o número de folhas das plantas tratadas com giberelina fosse menor em relação às plantas testemunhas. Segundo Almeida \& Pereira (1996), a transformação de primórdios foliares ocorre mais rápido nas plantas tratadas com $\mathrm{GA}_{3}$. Assim sendo, as plantas de D. nobile tratadas com giberelina tiveram o mesmo número de folhas das plantas testemunhas provavelmente porque, sob efeitos do fitorregulador, a maior velocidade do desenvolvimento e expansão foliar a partir de primórdios foliares compensou a perda inicial de algumas folhas nas plantas tratadas.

As folhas de plantas de $D$. nobile tratadas com $\mathrm{GA}_{3}$ apresentaram maior comprimento, equivalendo, em média, a um incremento de $44 \%$ (Tabela 1). As folhas das plantas testemunhas foram, em média, 56,09\% mais largas que as plantas tratadas com giberelina (Tabela 1). Auras (1997) também observou que a giberelina aumentou o tamanho das folhas de girassol, sugerindo que esse hormônio tem alguma participação ativa no controle da morfogênese das folhas. Além de aumentar a velocidade do desenvolvimento de primórdios foliares, o GA também promove aumento no tamanho das plantas intactas mediante estímulo tanto da divisão quanto do alongamento das células. As plantas de D. nobile tratadas com $\mathrm{GA}_{3}$ apresentaram menor largura de suas folhas (Tabela 1) porque, sob efeitos do ácido giberélico, a direção da expansão celular é longitudinal (RAVEN et al., 2001).

A epinastia, movimento nástico por crescimento, foi observada em algumas folhas de $D$. nobile tratadas com $\mathrm{GA}_{3}$. Nesse caso, a giberelina favoreceu uma maior taxa de crescimento na superfície superior da folha e, por isso, essas folhas curvaram-se para baixo, resultante do crescimento desigual.

\section{CONCLUSÃO}

O ácido giberélico nas concentrações de 50 a 400 mg.L $\mathrm{L}^{-1}$ é igualmente eficiente no alongamento de plantas Dendrobium nobile Lindl.

\section{REFERÊNCIAS BIBLIOGRÁFICAS}

ALMEIDA, J. A. S.; PEREIRA, M. F. D. A. Efeito de GA 3 e paclobutrazol no desenvolvimento vegetativo do girassol. Revista Brasileira de Fisiologia Vegetal, Brasília, v. 9, n. 1, p. 55-60, jan./abr. 1996

APPLICATION of gibberellic acid. Citrograph, Los Angeles, v. 81, n. 11, p. 3-16, Sept. 1996.

ARAÚJO, A. G. Crescimento in vitro e aclimatização de plântulas de orquídeas. 2004.78 p. Dissertação (Mestrado em Fitotecnia) - Universidade Federal de Lavras, Lavras, 2004.

AURAS, N. E. Efeitos do paclobutrazol sobre morfologia e anatomia foliar, crescimento de parte aérea, distribuição de biomassa e trocas gasosas em girassol. 1997. $88 \mathrm{f}$. Tese (Doutorado em Fisiologia Vegetal) - Universidade Federal de Viçosa, Viçosa, 1997.

CASPER, J. A.; TAYLOR, B. H. Growth and development of young "Loring" peach trees after foliar sprays of paclobutrazol and $\mathrm{GA}_{3}$. Hortscience, Alexandria, v. 24, n. 2, p. 240-242, Apr. 1989. 
CHEN, W. E.; LIU, H. Y.; LIU, Z. H.; YANG, L.; CHEN, W. H. Gibberellin and temperature influence carbohydrate content and flowering in Phalaenopsis. Physiologia Plantarum, Copenhagen, v. 90, n. 2, p. 391-395, Feb. 1994

COELHO, Y. S.; OLIVEIRA, A. A. R.; CALDAS, R. C. Efeitos do ácido giberélico $\left(\mathrm{AG}_{3}\right)$ no crescimento de porta-enxertos de citros. Pesquisa Agropecuária Brasileira, Brasília, v. 18, n. 11 , p. 1229-1232, nov. 1983.

CORDEIRO, J. A. D. Crescimento, diferenciação e produção em plantas de sorgo granífero Sorghum bicolor (L.) Moench, trataradas com os ácidos giberélico-3 e anaftalenoacético. 1979. 50 f. Dissertação (Mestrado em Fitotecnia) - Universidade Federal do Ceará, Fortaleza, 1979.

DAYKIN, A.; SCOTT, I. M.; FRANCIS, D.; CAUSTON, D. R. Effects of gibberellin on the cellular dynamics of dwarf pea internode developpement. Planta, Berlin, v. 203, n. 4, p. 526-535, Apr. 1997.

FARIA, R. T.; ILLG, R. D. Orquídea: Dendrobium nobile. In: TOMBOLATO, A. F. C.; COSTA, A. M. M. Micropropagação de plantas ornamentais. Campinas: Instituto Agronômico, 1998. p. 34-36.

FERREIRA, D. F. Análises estatísticas por meio do Sisvar para Windows versão 4.0. In: REUNIÃO ANUAL DA REGIAO BRASILEIRA DA SOCIEDADE INTERNACIONAL DE BIOMETRIA, 45., 2000, São Carlos. Anais... São Carlos: UFSCar, 2000. p. 255-258.

FRÁGUAS, C. B.; VILLA, F.; SOUZA, A. V.; PASQUAL, M.; DUTRA, L. F. Crescimento in vitro de plântulas de orquídeas oriundas da hibridação entre Cattleya labiata e Laelia itambana. Revista Ceres, Viçosa, v. 50, n. 292, p. 719-726, nov./dez. 2003.

JONES, W. E.; KUEHNLE, A. R.; ARUMUGANATHAN, K. Nuclear DNA content of 26 orchid (Orchidaceae) genera with emphasis on Dendrobium. Annals of Botany, New York, v. 82, n. 2, p. 189-194, Aug. 1998.

LEONEL, S.; RODRIGUES, J. D. Efeitos de giberelinas, citocininas e do nitrato de potássio no crescimento e desenvolvimento do porta-enxerto de limoeiro 'Cravo'. Scientia Agricola, Piracicaba, v. 53, n. 2/3, p. 261-266, maio/dez. 1996.

MELTIVIER, J. R. Citocininas e giberelinas. In: FERRI, M. G. Fisiologia vegetal. 2. ed. São Paulo: EDUSP, 1986. v. 2, cap. 4-5, p. 93-162.
MENEGUCCI, J. L. P.; AMARAL, A. M.; SOUZA SOBRINHO, F.; SOUZA, M. Efeito do GA e 2,4-D na época de colheita da laranja 'lima sorocaba'. Ciência e Agrotecnologia, Lavras, v. 25, n. 4, p. 878-889, jul./ago. 2001.

PIRES, E. P. J. Emprego de reguladores de crescimento em viticultura tropical. Informe Agropecuário, Belo Horizonte, v. 19, n. 194, p. 40-43, jul. 1998.

RAVEN, P. H.; EVERT, R. F.; EICHHORN, S. E. Biologia vegetal. Rio de Janeiro: Guanabara Koogan, 2001. 906 p.

ROSSELL, C. E. V. Obtenção de ácido giberélico por fermentação com Gibberella fujikoroi. 1971. 127 f. Dissertação (Mestrado em Ciências de tecnologia de Alimentos) Universidade Estadual de Campinas, Campinas, 1971.

SACHS, R. M.; ALNG, A.; BRETZ, C. F.; ROACH, J. Shoot histogenesis, subapical meristematics activity in a caulescent and action of gibberellic acid and AMO-1618. American Journal of Botany, Columbus, v. 47, n. 1, p. 260-266, Jan. 1960.

SHEEHAN, T. J. Recent advances in botany, propagation and physiology of orchids. Horticultural Reviews, New York, v. 5, n. 1, p. 279-315, 1983.

SIDAHMED, O. A. Effects of different levels of gibberellic acid $\left(\mathrm{GA}_{3}\right)$ on growth of sour orange (Citrus aurantium). Acta Horticulturae, The Hague, v. 84, n. 1, p. 165-169, Jan. 1978.

SPONSEL, V. M. Gibberellins in Pisum sativum: their nature, distribution and involvement in growth and development of the plant. Physiologia Plantarum, Copenhagen, v. 65, n. 2, p. 533-538, Feb. 1985.

SUZUKI, R. M.; KERBAUY, G. B.; ZAFFARI, G. R. Endogenous hormonal levels and growth of darkincubated shoots of Catasetum fimbriatum. Journal of Plant Physiology, Stuttgart, v. 161, n. 2, p. 929-935, 2004.

TAIZ, L.; ZEIGER, E. Plant physiology. 2. ed. Sunderland: Sinauer Associates, 1998. 792 p.

TREWAVAS, A. A how do plant growth substances work? Plant, Cell and Environment, Oxford, v. 4, n. 1, p. 203-228, Jan. 1981.

ZIMMERMAN, J. K. Role of pseudobulbs in growth and flowering of Catasetum viridiflavum (Orchidaceae). American Journal of Botany, Columbus, v. 77, n. 4, p. 533-542, Apr. 1990. 